\title{
ANALISA PERBANDINGAN KUALITAS BETON DENGAN AGREGAT HALUS QUARRY SUNGAI MARUNI MANOKWARI DAN KAMPUNG BUGIS SORONG
}

\author{
Wennie Mandela ${ }^{1}$, Hendrik Pristianto $^{2^{*}}$, Muhammad Arif $^{3}$ \\ ${ }^{1,2}$ Dosen Program Studi Teknik Sipil Universitas Muhammadiyah Sorong \\ ${ }^{3}$ Mahasiswa Program Studi Teknik Sipil Universitas Muhammadiyah Sorong \\ Jln. Pendidikan No 27 Kota Sorong, Papua Barat \\ *tekniksipilsorong@gmail.com
}

\begin{abstract}
Abstrak
Beton adalah gabungan dari beberapa material yang rumit, namun mudah dibuat bahkan oleh mereka yang tidak memiliki keahlian dan pengertian yang mendalam tentang teknologi beton. Namun apabila dari kesederhanaan itu salah, maka sering menghasilkan persoalan pada produk yang dihasilkan, diantaranya reputasi yang jelek pada beton. Agregat halus yang merupakan bahan utama dari beton yang mana agregat halus (pasir) yang berasal dari Quarry Sungai Maruni Manokwari dan Quarry Km 10 Kampung Bugis Sorong yang memadai dan mudah dijangkau, sifat serta mutunya akan diteliti untuk mengetuhui apakah material agragat halus sesuai dengan standard yang telah ditetapkan atau tidak. Tujuan penelitian ini adalah untuk memperoleh data tentang karakteristis dari agregat halus yang diambil dari quarry sungai maruni Manokwari dan Quarry Km 10 Kampung Bugis Sorong. Dan untuk mengetahui kuat tekan beton dengan menggunakan agregat halus yang diambil dari Quarry Sungai Maruni Manokwari dengan Quarry Km 10 Kampung Bugis Sorong. Penelitian yang dilaksanakan yaitu penelitian yang menggambil sampel dari Quarry Sungai Maruni Manokwari dan Sorong untuk periksa dan diuji di Laboratorium Beton Teknik Sipil Universitas Muhammadiyah Sorong. Hasil penelitian material yaitu hasil pengujian agregat halus Quarry Sorong mengandung kandungan lumpur sebesar 7,4\% dan Agregat halus Quarry Manokwari mengandung kandungan lumpur sebesar 4,8\%.
\end{abstract}

Kata Kunci : Beton, Agregat, Quarry

\section{PENDAHULUAN}

\subsection{Latar Belakang}

Beton adalah gabungan dari beberapa material yang rumit, namun mudah dibuat bahkan oleh mereka yang tidak memiliki keahlian dan pengertian yang mendalam tentang teknologi beton. Namun apabila dari kesederhanaan itu salah, maka sering menghasilkan persoalan pada produk yang dihasilkan, diantaranya reputasi yang jelek pada beton. Kualitas beton sangat tergantung pada sifat unsur masing-masing material. Beton memiliki kuat tekan yang tinggi sementara kuat tariknya kecil, oleh karena itu beton sebagai struktur bangunan sering dikombinasikan dengan tulangan baja untuk memperoleh kinerja Yang baik. Beton yang ditambahkan tulangan baja menjadi beton bertulang (reinforcet concrete), dan jika ditambahkan lagi dengan baja prategang akan menjadi beton pratekan (preestresset concrete).

Dalam permasalahan ini kami penulis tertarik pada agregat yang merupakan bahan utama dari beton yang mana agregat halus (pasir) yang berasal dari quarry sungai maruni Manokwari dan quarry $\mathrm{km} 10$ kampung bugis Sorong yang memadai dan mudah dijangkau, sifat serta mutunya akan diteliti untuk mengetuhui apakah material agragat halus sesuai dengan standard yang telah ditetapkan atau tidak.

\subsection{Tujuan Penelitian}

Tujuan dari penelitian ini adalah :

1. Untuk memperoleh data tetang karakteristik dari agregat halus yang diambil dari quarry sungai Maruni dan quarry Km. 10 Kampung Bugis Sorong.

2. Untuk mengetahui perbandingan kuat tekan beton dengan menggunakan agregat halus yang diambil dari quarry Sungai Maruni Manokwari dengan quarry Km. 10 Kampung Bugis Sorong. 


\section{METODOLOGI}

\subsection{Lokasi Penelitian}

Untuk pengambilan material agregat halus (pasir) yaitu quarry Manokwari dan Sorong, yang merupakan material lokal yang ada di Papua Barat dengan waktu penelitian mulai bulan Maret sampai selesai

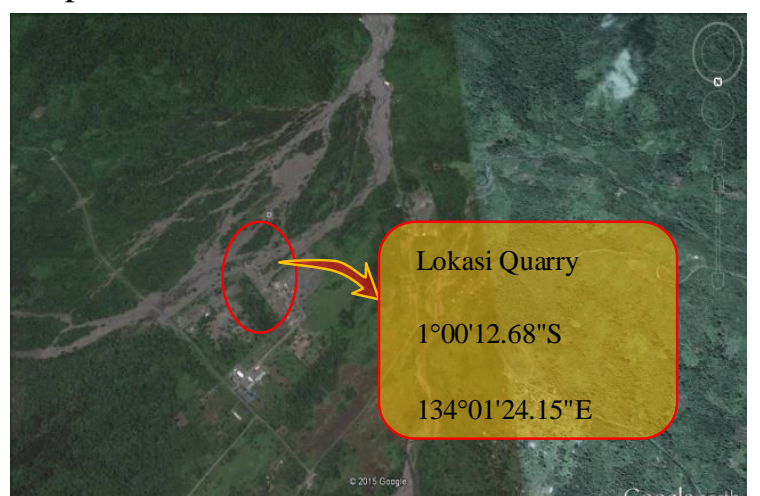

(a)

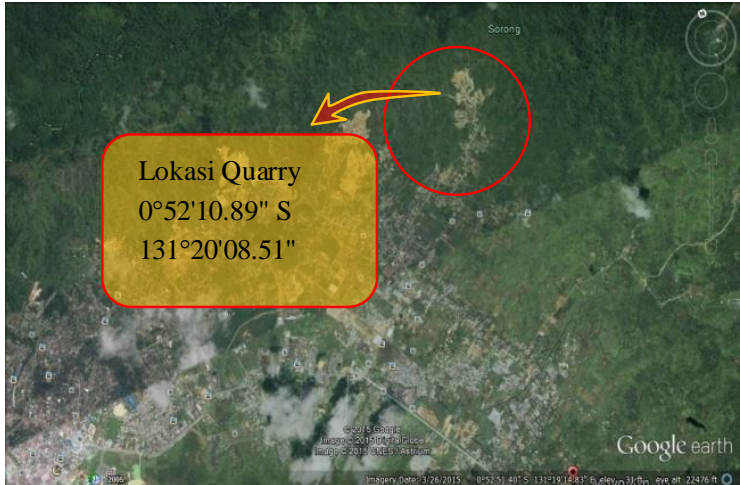

(b)

Gambar 1. (a) Koordinat Quarry Maruni Manokwari dan (b) Quary Sorong

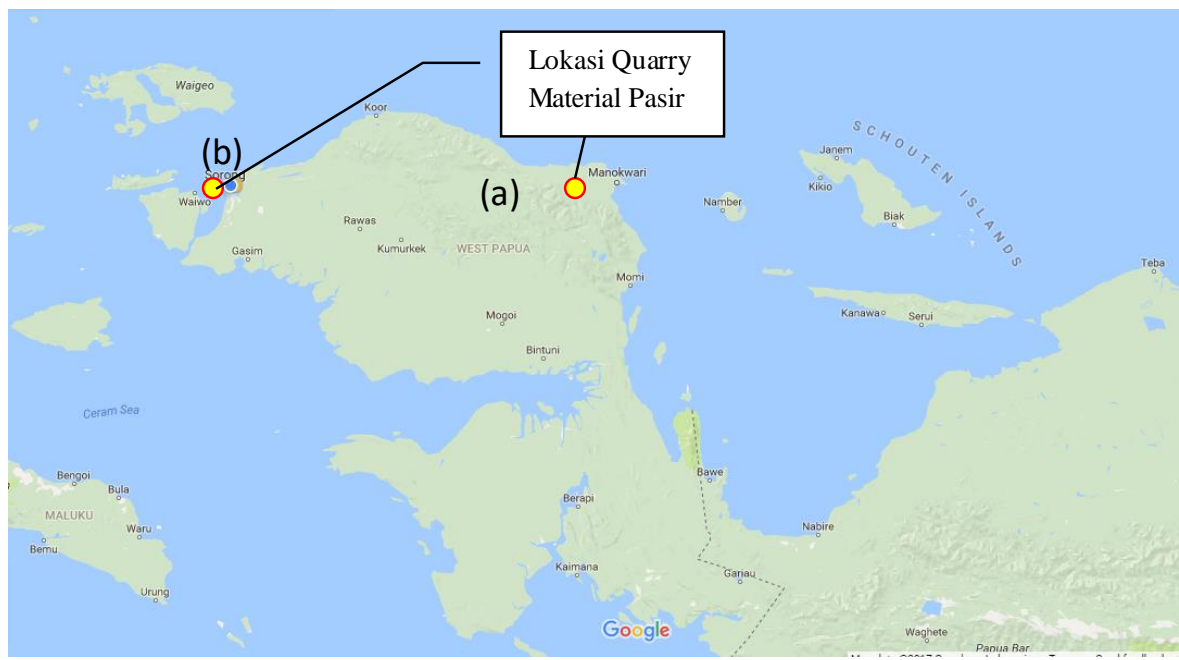

Gambar 2. Lokasi quarry pasir terhadap peta Papua

\subsection{Tahap Penelitian}

Secara keseluruhan penelitian ini dilakukan dengan beberapa tahapan, yaitu peninjauan lokasi quarry, pengambilan material, pengujian material agregat halus, perencanaan campuran beton, perawatan benda uji, pengujian kuat tekan beton.

\subsection{Kebutuhan Data}

Untuk memperoleh data dalam penelitian ini digunakan beberapa cara yaitu :

1. Pemeriksaan karakteristik agregat halus (pasir).

2. Perencanaan campuran beton.

3. Pengujian kuat tekan beton. 


\subsection{Bagan Alir Penelitian}

Dari data tersebut diproses sesuai dengan formula pasta prosedur pengujian untuk mendapatkan data mentah, dengan demikian pengolahan data dapat dilihat pada diagram alur sebagai berikut :

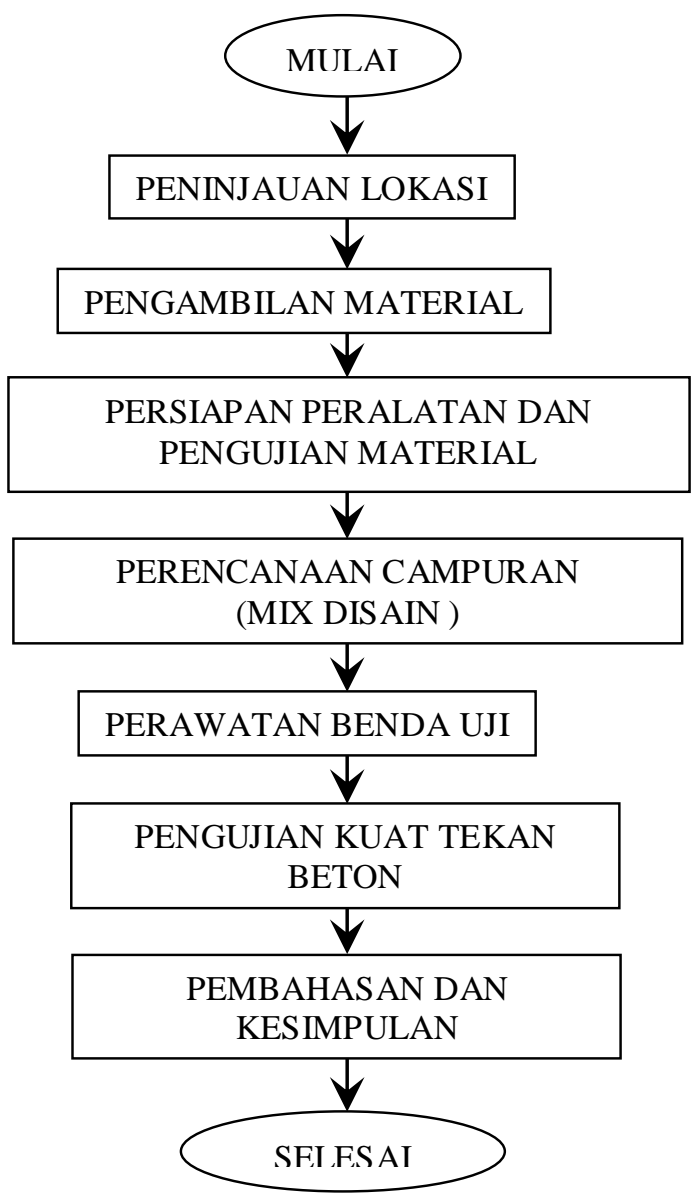

\section{Gambar 3. Diagram alir penelitian}

\section{HASIL DAN PEMBAHASAN}

\subsection{Hasil Pengujian Material}

Pada Untuk menentukan komposisi campuran beton dilakukan pengujian material yaitu kandungan lumpur dalam pasir, modulus halus butir, berat volume agregat, berat jenis agregat dan penyerapan air. Hasil dari pengujian dapat dilihat pada tabel berikut ini :

Tabel 1. Hasil Pengujian Material

\begin{tabular}{lcc}
\hline \multicolumn{1}{c}{ Penelitian } & $\begin{array}{c}\text { Agregat halus } \\
\text { (Sorong) }\end{array}$ & $\begin{array}{c}\text { Agregat halus } \\
\text { (Manokwari) }\end{array}$ \\
\hline Kadar lumpur dalam pasir (\%) & 7,4 & 4,8 \\
Modulus halus butir & 2,761 & 5,025 \\
Berat isi padat $\left(\mathrm{gr} / \mathrm{cm}^{3}\right)$ & 1,6364 & 1,7985 \\
Berat isi gembur $\left(\mathrm{gr} / \mathrm{cm}^{3}\right)$ & 1,4452 & 1,5883 \\
Berat jenis (SSD) & 2,057 & 2,50 \\
Penyerapan air $(\%)$ & 7,991 & 0,048 \\
Ukuran agregat maksimum $(\mathrm{mm})$ & 40 & 40 \\
\hline & Sumber : Hasil Pengujian Laboratorium
\end{tabular}




\subsection{Kelecakan / Workability}

Kemudahan, pengerjaan dapat dilihat dari nilai slump yang identik dengan tingkat keplastisan beton dan nilai slump berpengaruh juga pada kuat desak beton. Adukan beton yang memiliki nilai slump kecil/rendah akan menghasilkan kuat desak yang tinggi :

Tabel 2. Nilai Slump dan Kebutuhan Air Agregat Sorong

\begin{tabular}{cccc}
\hline $\begin{array}{c}\text { Kuat desak yang } \\
\text { disyaratkan }\left(\mathrm{f}^{\prime} \mathrm{c}\right)\end{array}$ & $\begin{array}{c}\text { Slump } \\
(\mathrm{cm})\end{array}$ & $\begin{array}{c}\text { Kebutuhan air hasil } \\
\text { perencanaan }(\mathrm{kg})\end{array}$ & $\begin{array}{c}\text { Jumlah air yang } \\
\text { digunakan }\end{array}$ \\
\hline 30 & 8 & 5,64 & 6,14 \\
\hline
\end{tabular}

Sumber : Hasil Pengujian Laboratorium

Tabel 3. Nilai Slump Dan Kebutuhan Air Agregat Manokwari

\begin{tabular}{cccc}
\hline $\begin{array}{c}\text { Kuat desak yang } \\
\text { disyaratkan }\left(\mathrm{f}^{\prime} \mathrm{c}\right)\end{array}$ & $\begin{array}{c}\text { Slump } \\
\mathrm{( \textrm {cm } )}\end{array}$ & $\begin{array}{c}\text { Kebutuhan air hasil } \\
\text { perencanaan }(\mathrm{kg})\end{array}$ & $\begin{array}{c}\text { Jumlah air yang } \\
\text { digunakan }\end{array}$ \\
\hline 30 & 8,5 & 5,64 & 6,14 \\
\hline & & Sumber : Hasil Pengujian Laboratorium
\end{tabular}

Pada tabel diatas nilai slump untuk semua nilai kuat desak yang disyaratkan masuk spesifikasi yang telah ditetapkan dalam perhitungan mix design yaitu 75-150 mm. Akan tetapi penggunaan air tidak sesuai dengan kebutuhan air yang direncanakan, hal ini disebabkan oleh material agregat halus (pasir) yang digunakan pada saat pencampuran tidak dalam kondisi SSD sepenuhnya.

\subsection{Langkah Perhitungan Mix Design Metode SNI}

Hasil Diketahui data - data sebagai berikut :

a) Kuat desak yang disyaratkan $f^{\prime} c=30 \mathrm{MPa}$, untuk umur 7, dan 28 hari (benda uji silinder)

b) Semen yang dipakai semen Portland tipe I merek tonasa $50 \mathrm{~kg}$

c) Tinggi slump yang disyaratkan $75-150 \mathrm{~mm}$

d) Ukuran butiran agregat kasar $40 \mathrm{~mm}$

e) Susunan butir agregat halus masuk dalam gradasi nomor 2

Data agregat halus dan agregat kasar sbb :

Tabel 4. Gradasi Dan Sifat Fisik Agregat

\begin{tabular}{lccc}
\hline Ukuran ayakan & $\begin{array}{c}\text { Agregat halus } \\
\text { (Sorong) } \\
\text { lolos ayakan } \%\end{array}$ & $\begin{array}{c}\text { Agregat halus } \\
\text { (manokwari) } \\
\text { lolos ayakan \% }\end{array}$ & $\begin{array}{c}\text { Agregat kasar } \\
\text { lolos ayakan \% }\end{array}$ \\
\hline $1 \frac{1}{1 / 2}(38,2 \mathrm{~mm})$ & 100 & 100 & - \\
$3 / 4 "(19,1 \mathrm{~mm})$ & 100 & 96,6 & - \\
$1 / 2 "(12,7 \mathrm{~mm})$ & 96,1 & 85,65 & 100 \\
No. $4(4,75 \mathrm{~mm})$ & 52,2 & 56,5 & 12,5 \\
No. $10(2,0 \mathrm{~mm})$ & 29,65 & 33,45 & 0,24 \\
No. $40(0,4 \mathrm{~mm})$ & 23,4 & 16,3 & 0 \\
No. $100(0,15 \mathrm{~mm})$ & 23,4 & 6,65 & 0 \\
No. $200(0,075 \mathrm{~mm})$ & & 2,05 & 0 \\
\hline
\end{tabular}

Tabel 5. Sifat Fisik Agregat

\begin{tabular}{lccc}
\multicolumn{1}{c}{ Sifat agregat } & Pasir sorong & Pasir manokwari & $\begin{array}{c}\text { Kerikil (batu } \\
\text { pecah) }\end{array}$ \\
\hline Berat jenis SSD & 2,057 & 2,50 & 2,877 \\
Penyerapan air & 7,991 & 0,048 & 2,88 \\
\hline
\end{tabular}

\subsection{Hitungan Kebutuhan Material Per- $\mathrm{m}^{3}$ Beton Dengan Agregat Halus Sorong}

Bagian Diketahui data - data sebagai berikut :

1) Kuat desak yang disyaratkan $f^{\prime} c=30 \mathrm{MPa}$, untuk umur 7 hari dengan benda uji silinder 
2) Nilai deviasi standar digunakan tabel1 lampiran yang didasarkan pada tingkat pengendalian mutu pekerjaan, diambil mutu pekerjaan cukup, maka $\mathrm{Sd}=5,6 \mathrm{MPa}$. Gunakan tatapan statistic 1,64.

3) Nilai tambah, $\mathrm{M}=1,64 \times \mathrm{Sd}=1,64 \times 5,64=9,184$ digunakan $10 \mathrm{MPa}$

4) Kuat tekan rata-rata yang ditargetkan :

$f^{\prime} c r=f^{\prime} c+M=30+10=40 \mathrm{MPa}$

5) Jenis semen tipe I merk tonasa $50 \mathrm{~kg}$

6) Jenis agregat yang digunakan :

a. Agregat halus : pasir alami

b. Agregat kasar : batu pecah

7) Factor Air Semen

a. FAS maksimum ditentukan 0,6

b. Dari tabel 2 lampiran untuk agregat kasar batu pecah dan semen tipe I, kuat tekan silinder umur 7 hari $f^{\prime} c=27 \mathrm{MPa}$ dengan fas $=0,5$

c. Digunakan grafik 1 lampiran hubungan antara factor air semen dan kuat tekan rata-rata sehingga didapatkan nilai fas 0,5 dengan $f^{\prime} c r=40 \mathrm{MPa}$.

Untuk lebih jelas dapat dilihat pada grafik berikut ini :

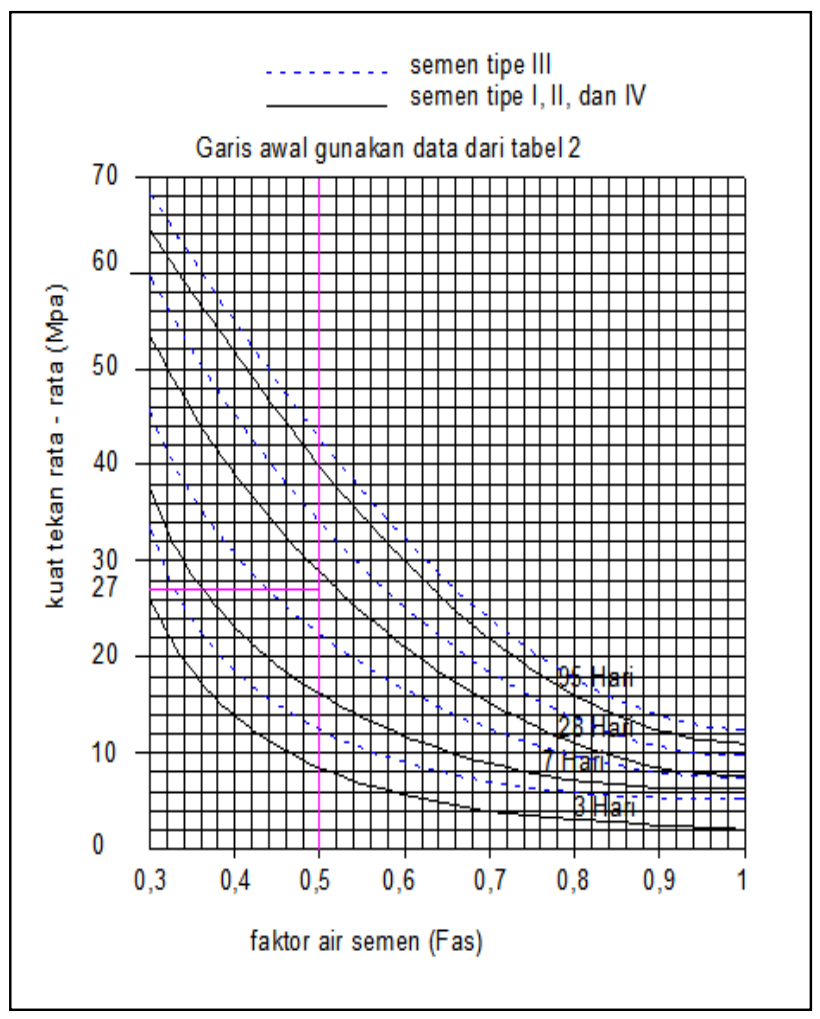

\section{Gambar 4. Grafik Faktor Air Semen}

8) Factor air semen maksimum yang ditetapkan adalah 0,6 dan nilai fas yang diperoleh berdasarkan grafik 1 lampiran adalah 0,5 maka digunakan untuk perhitungan selanjutnya adalah nilai fas yang maksimum yakni 0,6 .

9) Slump ditetapkan sebesar75-150mm

10) Ukuran agregat maksimum $40 \mathrm{~mm}$

11) Kadar air bebas ditentukan dari tabel 3 lampiran,untuk nilai slump 60-180, ukuran butir maksimum $40 \mathrm{~mm}$, dan agregat yang digunakan terdiri dari agregat tak dipecah (pasir) dan agregat kasar batu pecah, yaitu :

a. Kadar air bebas untuk agregat tidak dipecah ( pasir) $175 \mathrm{~kg} / \mathrm{m}^{3}$

b. Kadar air bebas untuk agregat dipecah ( batu pecah) $205 \mathrm{~kg} / \mathrm{m}^{3}$

c. Sehingga jumlah air yang diperlukan :

$2 / 3 \times \mathrm{Wh}+1 / 3 \times \mathrm{Wk}=2 / 3 \times 175+1 / 3 \times 205=185 \mathrm{~kg} / \mathrm{m}^{3}$ 
12) Kadar semen $=$ jumlah air $/$ fas $=185 \mathrm{~kg} / \mathrm{m}^{3} / 0,6=308,333 \mathrm{~kg} / \mathrm{m}^{3}$

13) Kadar semen maksimum tidak ditetapkan, diabaikan.

14) Kadar semen minimum $=275 \mathrm{~kg} / \mathrm{m}^{3}$ (dalam ruang dan keadaan sekeliling nonkrososif, tabel 4 lampiran), berarti kadar semen $308,333 \mathrm{~kg} / \mathrm{m}^{3}$ sudah memenuhi.

15) Bila kadar semen hasil hitungan (12) lebih kecil dari kadar semen minimum maka digunakan kadar semen minimum, tetapi apabila hasil hitungan (12) lebih besar dari kadar semen minimum maka digunakan hasil hitungan (12). Dalam data ini digunakan hasil hitungan sebesar $=308,333 \mathrm{~kg} / \mathrm{m}^{3}$.

16) Factor air semen disesuaikan apabila kadar semen hasil hitungan (12) lebih kecil dari kadar semen minimum dalam hal ini fas harus dihitung kembali. Untuk data ini hitungan (12) lebih besar dari kadar semen minimum sehingga fas tetap 0,6 untuk hitungan selanjutnya.

17) Susunan butir agregat halus ditetapkan masuk gradasi No.2 (grafik) :

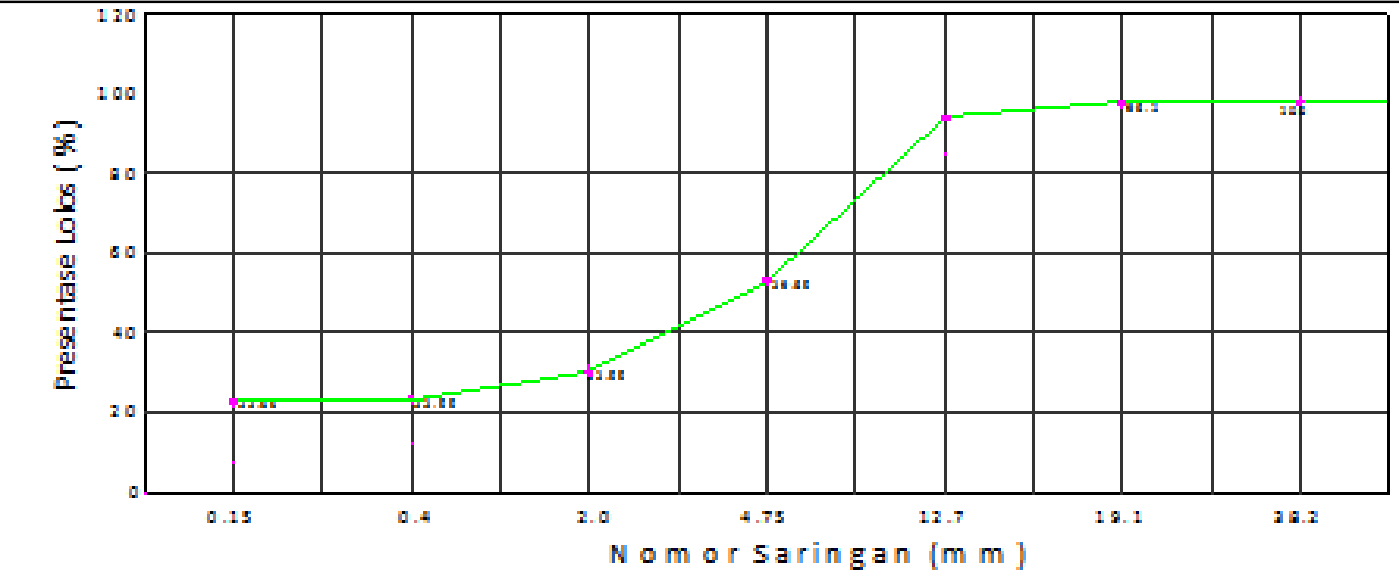

\section{Gambar 5. Grafik Gradasi Pasir}

18) Susunan butir agregat kasar seperti pada tabel soal.

19) Mencari persentase agregat halus (agregat yang lebih kecil dari $4.8 \mathrm{~mm}$ ). Persentase agregat halus dicari dengan grafik 14 lampiran (ukuran butir maksimum $20 \mathrm{~mm}$ ), dengan nilai slump 60-180, fas 0,6 dan susunan masuk daerah gradasi No. 2 diperoleh persentase agregat halus $43 . \%$.

Tabel 6. Perencanaan Campuran Beton $f^{\prime} c=30$ MPa.

\begin{tabular}{clcll}
\hline No & \multicolumn{1}{c}{ Uraian } & Nilai & Satuan & Tabel/grafik/hitungan \\
\hline 1 & Kuat tekan yang disyaratkan & 30 & $\mathrm{MPa}$ & Ditetapkan \\
2 & Deviasi standar (Sd) & 5,6 & $\mathrm{MPa}$ & Tabel 1lampiran \\
3 & Nilai tambah (M) & 10 & $\mathrm{MPa}$ & $1.64 \times$ Sd \\
4 & Kuat tekan ditargetkan & 40 & $\mathrm{MPa}$ & $(1)+(3)$ \\
5 & Jenis semen & Tonasa tipe I & & Ditetapkan \\
6 & Jenis agregat halus pasir alami & & & \\
7 & Factor air semen (FAS) & 0,5 & & Grafik 1 lampiran \\
8 & Factor air semen maksimum & 0,6 & & Ditetapkan \\
9 & Slump & $75-150$ & $\mathrm{~mm}$ & Ditetapkan \\
10 & Ukuran agregat maksimum & 40 & $\mathrm{~mm}$ & Ditetapkan \\
11 & Kadar air bebas & 185 & $\mathrm{Kg} / \mathrm{m}^{3}$ & Tabel 3 lampiran \\
12 & Jumlah semen & 308,33 & $\mathrm{Kg} / \mathrm{m}^{3}$ & $(11) /(7)$ \\
13 & Jumlah semen maksimum & & & Tidak ditentukan \\
14 & Jumlah semen minimum & 275 & $\mathrm{Kg} / \mathrm{m}^{3}$ & Tabel 4 lampiran \\
15 & Jumlah yang dipakai & 308,33 & $\mathrm{Kg} / \mathrm{m}^{3}$ & $(12)>(14)$ \\
\hline
\end{tabular}


Tabel 6. Perencanaan Campuran Beton $f^{\prime} c=30$ MPa (lanjutan)

\begin{tabular}{llccl}
\hline No & \multicolumn{1}{c}{ Uraian } & Nilai & Satuan & Tabel/grafik/hitungan \\
\hline 16 & Factor air semen disesuaikan & 0,6 & & \\
17 & Susunan butiran agregat halus & Gradasi 2 & & Ditetapkan \\
18 & Susunan agregat kasar atau gabungan & & & Masuk zona A-B \\
19 & Persen agregat halus & 43. & $\%$ & Grafik 14 lampiran \\
20 & Berat jenis relatif agregat SSD & 2,7 & $\mathrm{Gr} / \mathrm{m}^{3}$ & Hitungan \\
21 & Berat isi beton & 2430 & $\mathrm{Kg} / \mathrm{m}^{3}$ & Grafik 16 lampiran \\
22 & Kadar agregat gabungan & 2121,67 & $\mathrm{Kg} / \mathrm{m}^{3}$ & $(21)-(15)-(11)$ \\
23 & Kadar agregat halus & 912,32 & $\mathrm{Kg} / \mathrm{m}^{3}$ & $(190 \times(22)$ \\
24 & Kadar agregat kasar & 1209,35 & $\mathrm{Kg} / \mathrm{m}^{3}$ & $(22)-(23)$ \\
25 & Proporsi campuran & & \multicolumn{2}{c}{ Agragat } \\
& Jumlah bahan & Semen & Air & Halus Kasar \\
& Tiap m ${ }^{3}$ & 308,33 & 185 & $912,32 \quad 1209,35$ \\
& Tiap campuran 5 benda uji 0,0305 & 9,40 & 5,64 & $27,83 \quad 36,89$ \\
\hline
\end{tabular}

Sumber : Hasil Pengujian Laboratorium

\section{KESIMPULAN}

Dari Berdasarkan hasil penelitian yang telah dilaksanakan penulis dapat menyimpulkan bahwa :

1. Karakteristik dari agregat halus yang diuji :

a. Hasil pengujian Agregat halus quarry Sorong mengandung kandungan lumpur sebesar 7,4 \%

b. Hasil pengujian Agregat halus quarry Manokwari mengandung kandungan lumpur sebesar $4,8 \%$

c. Dari analisa saringan yang dilaksanakan, Modulus halus butir gregat halus quarry Sorong adalah 2,761 dan Modulus halus agregat halus quarry Manokwari adalah 5,025.

2. Perbandingan kuat tekan beton:

a. Nilai kuat tekan hasil pengujian sampel beton Sorong sebagai berikut :

Umur 7 hari $=5,7607 \mathrm{MPa}$

Umur 14 hari $=8,0355 \mathrm{MPa}$

Umur 28 hari $=13,0153 \mathrm{MPa}$

b. Nilai kuat tekan hasil pengujian sampel beton Manokwari sebagai berikut

Umur 7 hari $=6,1681 \mathrm{MPa}$

Umur 14 hari $=8,4426 \mathrm{MPa}$

Umur 28 hari $=14,0339 \mathrm{MPa}$.

\section{DAFTAR PUSTAKA}

Mulyono Tri, 2003. Teknologi Beton. Jakarta

Peraturan Beton Bertulang Indonesia,1971, cetakan ke 7 april 1979. Penerbit: Direktorat Penyelidikan Masalah Bangunan.

Pujo Aji Ir. MT.Dr. techn. \& Rachmmat Purwono Ir. MSc. Prof. IP-U HAKI. 2009. Pengendalian Mutu Beton. Surabaya: ITS Press

SNI 03- 2834-1993, Tentang Tata Cara Pembuatan Rencana Campuran Beton Normal.

SNI 03 - 2834 - 2000, Tentang Tata Cara Pembuatan Rencana Campuran Beton Normal.

SNI 03 - 2847 - 2002, Tentang Tata Cara Perhitungan Struktur Beton Untuk Bangunan Gedung.

SNI 1974 - 2011, Tentang Cara Uji Kuat Tekan Beton Dengan Benda Uji Silinder.

Spesifikasi Umum 2011, Revisi - 3, Tentang Struktur Beton. 